\title{
Oil Price Volatility and Stock Price Volatility: Evidence from Nigeria
}

\author{
A.E. Uwubanmwen, Ph.D \\ O.G. Omorokunwa \\ Department of Banking and Finance, University of Benin, Benin City, Nigeria \\ Email:osazee.omorokunwa@uniben.edu
}

\section{Doi:10.5901/ajis.2015.v4n1p253}

\begin{abstract}
The goal of this study is to empirically estimate a model that helps to explain the behaviour of stock price volatility, movements in oil prices and real exchange rates in Nigeria using quarterly data from 1990 to 2012. Statistical and econometric techniques such as the Error Correction Mechanism (ECM) and the Bi-variate GARCH model were used to test for the relationships and to check if volatility in oil prices are transmitted to stock prices in Nigeria. The study showed that oil price volatility generates and stimulates stock prices volatility in Nigeria. The authors recommended that the excess crude oil revenues should be transform into physical capital and infrastructure rather than distribute the windfalls to the state and local government, a situation that ensures easy transmission of oil prices into the Nigerian economy.
\end{abstract}

Keywords: GARCH, Nigeria, Oil price, Stock price, Volatility.

\section{Introduction}

Oil is the livewire of any country because of its diverse use. The importance of oil on economic activities can be felt when there is fluctuation in the prices of oil. As economic activities increases as a result of economic growth, the demand for oil increases. The prospects of future oil supply are highly uncertain considering persistent political instability in exporting countries and the uncertainty regarding the discovery of new reserves. As an outcome of such uncertainties, oil prices could experience further (increasingly) drastic fluctuations in the future (Rentschler, 2013). Sauter and Awerbuch (2003) posit that a rise in oil prices leads to a decrease in economic activities. Basher and Sadorsky (2006) speculate that future oil demand is difficult to predict but is generally highly correlated with the growth in industrial production. And countries with rapid economic growth are the ones most likely to dramatically increase their demand for oil.

Omorokunwa and Oviasogie (2013) conceive that the stock markets of the developed economy are generally assumed to be more liquid and efficient compared to their counterparts in emerging economies like Nigeria. Extant studies also provide evidence suggesting the existence of higher volatility and price changes in emerging stock markets. Volatility of stock price has become increasingly important for market participants, regulators and academics alike. Some researchers see the causes of volatility in the arrival of new and unanticipated information that alters expected return on a stock. Thus, changes in the price volatility of the stock market would merely reflect changes in the local or global economic environment.

Financial literatures are filled with theoretical and empirical evidence of the relationship between oil price and stock market volatility in developed economies. However in developing countries like Nigeria, there is a scarcity of empirical evidence on the effect of oil price volatility on stock price volatility. Thus the study seeks to close this gap by raising the following question: What is the relationship between oil prices volatility and stock price volatility?

Thus the objectives of this paper are to examine the direction of oil price volatility and stock prices volatility, and to investigate the relationship between oil price volatility and stock price volatility.

\section{Literature Review}

Basher and Sadorsky (2006) posit that energy, financial markets and the economy are all unequivocally connected together on a country's path to economic growth. When the demand for oil outwit it supply they tend to be an increase in oil price. Global unforeseen disparity in oil demand and supply, geopolitics, institutional arrangements like OPEC, and the dynamics of the futures market according to Sadorsky (2004) can generate oil price volatility. Sauter and Awerbuch 
(2003) hypothesize that an increase in oil prices and price volatility serve to suppress economic activities and diminish the values of assets.

The more a country engages in oil trade, the more it is open to the elements of price shocks on global commodity markets (Rentschler, 2013). Pindyck (1991) argues that changes in energy prices create ambiguity about future energy prices, causing firms to postpone irreversible investment decisions in reaction to the outlook for profits. Hassan and Ratti (2012) argue that oil price volatility influence stock prices through affecting expected cash flows and discount rates. Oil price shocks affect corporate cash flow since oil is an input in production and because oil price changes can influence the demand for output at industry and national levels. Rentschler (2013) posits that the impacts of sudden changes in oil prices can have detrimental effects and repercussions throughout the economy, disturbing macro-indicators such as employment, trade balance, inflation and public accounts, as well as stock market prices and exchange rates.

Also oil price shocks on the international market might be augmented in specific countries, depending on the respective Dollar exchange rate and prevailing inflationary pressures. Oil price instability reduces planning horizons, cause firms to postpone investments and require expensive reallocation of resources (Rentschler 2013). This may be a particularly profound problem in budget constrained developing countries, like Nigeria, which rely on oil exports as a main source of finance.

Arouri, Lahiani and Nguyen (2011) investigate the six countries members of the Gulf Cooperation Council (GCC) from 2005-2010 and find the existence of significant return and volatility spillovers between world oil prices and GCC stock markets. Basher and Sadorsky (2006) investigate the relationship between oil price risk and stock market returns in 21 emerging stock markets and find strong evidence that oil price risk impacts stock price returns in emerging markets.

Shaharudin, Samad and Bhat (2009) examine the effect of oil prices movements on the stock price of oil and gas companies in the US, India and UK and find the existence of significant short run and long run relationship between oil price and the oil stocks including the effect of the other variables such as interest rate and the stock index. Also they find that oil price volatility transmission has a persistent effect on the volatility of the stocks of the oil companies in all the countries that were studied.

Park and Ratti (2007) examine the U.S. and 13 European countries and find that increased volatility of oil prices significantly depresses real stock returns in the European countries. And that the contribution of oil price shocks to variability in real stock returns in the U.S. and most other countries is greater than that of interest rate. They also find that increase in real oil price significantly raises the short-term interest rate in the U.S. and eight out of 13 European countries within one or two months. Counter to findings for the U.S., there is no evidence of asymmetric effects on real stock returns of positive and negative oil price shocks for any of the European countries.

Agren (2006) studies the weekly stock market data for Germany, Japan, Sweden, the United Kingdom, and the United States, from 1989 to 2005. And finds strong evidence of volatility spillover for Germany, Japan, and the U.K. Out of these, German and British stock markets seem to have an asymmetric volatility-response to oil shocks, meaning that positive shocks affect stock market volatility more than negative ones do. Evidence of volatility spillover from oil prices to U.S. stocks is found, but is considered rather weak since it does not hold under some intuitively appealing parameter restrictions. No support for oil price volatility spillover to the Swedish stock market is presented over the sample period. Furthermore, empirical evidence is found that oil price changes have an impact on U.S. stock returns, and some evidence is provided that supports the asymmetry of oil price volatility.

Ramos and Veiga (2010) examine 43 stock markets and find that for developed countries stock market that oil price spikes depress international stock markets, but oil price drops do not necessarily increase stock market returns. And that the volatility of oil prices has a negative impact on international stock market returns. While emerging market returns are not sensitive to oil price variations. In addition, the asymmetry of oil price changes impacts oil volatility; i.e., when oil prices soar, oil volatility also increases, while negative oil price changes dampen volatility.

\section{Methodology}

A major aspect of the study is to investigate whether volatility in oil prices are transmitted into stock price volatility. Based on the structure within the study, three empirical methodologies will be used. The first one is the estimation of oil price and real effective exchange rate volatility by means of GARCH $(1,1)$ technique. The second method is the cointegration and error correction model technique which will be used to determine the relationship between the real effective exchange rate and the independent variables of the model. The third method is the model developed to show the spillover effect, namely the Bi-Variate GARCH model. The purpose of employing these three methodologies is based on the fact that the study seeks to show the relationship between oil price volatility and the stock market and also to indicate 
the pattern of volatility in the market as well as whether the volatility in the oil prices are being transmitted into the stock market. The error correction model addresses the goal of estimating a relationship between the variables while the GARCH and bi-variate GARCH models are used to show volatility in the market and the transmission volatility across systems. Hence, the three methods used in the study help to address the objectives of the study.

\subsection{The Error Correction Model}

The pattern of investigation in this study indicates that a function that relates stock prices with oil price volatility is devised. Though oil price volatility relationship with stock prices has only a general theoretical foundation, we devise that the two variables are related through the real naira exchange rate. As the oil prices fluctuate, the pass-through variable for its effect on the financial sector of the economy is the real exchange rate since relative prices would be affected. Thus, in our model, stock prices are hypothesized to depend on oil price volatility as well as the real exchange rate. The functional form of the model is presented as:

$\mathrm{SP}=\mathrm{f}(\mathrm{OPV}, \mathrm{REER})$

Where:

$\mathrm{SP}=$ stock prices;

OPV = Oil price volatility;

$\mathrm{REER}$ = real exchange rate

Stock price movement is a short term factor that requires dynamic modeling. Hence, the model specified is an error correction mechanism (ECM) that shows the pattern of short run behavior of the dependent variable in the face changes in the explanatory variables. The ECM is specified as:

$\Delta S P V_{t}=a_{0}+a_{1} \Delta S P V_{t-1}+a_{2} \Delta O P V_{t-i}+a_{3} \Delta R E E R_{t-i}+\delta E C M_{t-1}+\varepsilon$

$\mathrm{ECM}$ is error correction mechanism

Where $a_{0}-a_{3}$ are the coefficients to be estimated, $\delta$ is the ECM term, and $\varepsilon$ is the stochastic term. The i's in model indicate lag length which will be determined under an autoregressive distributed lag structure using the Akaike Information Criterion (AIC) and the Scharze Information Criterion (SIC).

\subsection{GARCH (1,1) Model}

The oil price volatility and stock price volatility will first be generated from the oil price by means of the GARCH $(1,1)$ technique. Autoregressive Conditional Heteroskedasticity (ARCH) models are specifically designed to model and forecast conditional variances. The variance of the dependent variable is modeled as a function of past values of the dependent variable and independent or exogenous variables. This method assumes that the autocorrelation and heteroskedasticity terms are both of the first order. It is the basic form of the GARCH estimates and is easily amenable to various time series conditions especially when the aim is to generate volatility (Bollerslev, Chou, and Kroner, 1992).

\subsection{Volatility Spillover Effect Model}

According to the empirical literature, the information flow across various international markets (i.e., correlation in the first moment) may not be significant and visible; however, it may a have high volatility effect (correlation in the second moment). Volatility has been considered a better proxy of information by Clark (1973) and Ross (1983). The ARCH model, which was developed by Engle (1982) and later generalized by Bollerslev (1986), is one of the most popular methods for modeling the volatility of high-frequency financial time series data.

In this study, the focus is on whether volatility in oil prices in the international market is transmitted into the Nigerian stock market. This requires a two-equation model that should be solved simultaneously. Following Mensi et al. (2013) the Bi-Variate GARCH model is used in the estimation to allow for a focus on the interdependence of the conditional changes, conditional volatility and conditional correlations between the oil prices and stock price volatility. This model was proposed by Ling and McAleer (2003) and later applied by several researchers, such as Chan et al. (2005), Hammoudeh et al. (2009) and Arouri et al. (2011). In its basic for, the model uses the multivariate Vector Conditional Heteroskedasticity (VECH) model of Bollerslev (1990) as a special case in which correlations between system shocks are assumed to be constant to ease the estimation and inference procedure. This is the method that is adopted in this study.

The conditional mean equation of the $\operatorname{VECH}(1,1)$ system is given by:

$Y_{t}=c+\phi T_{t-1}+\varepsilon_{t}$ 
$\varepsilon_{\mathrm{t}}=h_{t}^{\frac{1}{2}} \eta_{t}$

where:

$\mathrm{Yt}=\left(\mathrm{SPV}_{\mathrm{t}}, \mathrm{OPV} \mathrm{V}_{\mathrm{t}}\right.$, in which SPV is stock price volatility and OPV is as earlier defined at time $\mathrm{t}$.

$\varepsilon_{\mathrm{t}}=\left(\varepsilon_{t}^{r e e r}, \varepsilon_{t}^{o p v}\right)$, where $\varepsilon_{t}^{s p v}$ and $\varepsilon_{t}^{o p v}$ are the residual of the mean equations for stock price and oil price volatility respectively.

$\eta_{t}=\left(\eta_{t}^{\text {reer }}, \eta_{t}^{o p v}\right)=$ refers to the innovation and is an iid distributed random vector (see Mensi, 2013).

$h_{t}^{\frac{1}{2}}$ is a diagonal matrix containing the conditional variances of $s p v_{t}$ and opvt respectively. These variances may be respectively represented as $\left(h_{t}^{s p v}, h_{t}^{o p v}\right)$. Thus based on the VECH analysis, the associated variance equations for the two variables are given as:

$$
\begin{aligned}
& h_{t}^{s p v}=C_{s p v}+\alpha_{s p v}\left(\varepsilon_{t-1}^{s p v}\right)^{2}+\beta_{s p v} h_{t-1}^{s p v}+\alpha_{o p v}\left(\varepsilon_{t-1}^{o p v}\right)^{2}+\beta_{o p v} h_{t-1}^{o p v} \\
& h_{t}^{o p v}=C_{o p v}+\alpha_{o p v}\left(\varepsilon_{t-1}^{o p v}\right)^{2}+\beta_{o p v} h_{t-1}^{o p v}+\alpha_{s p v}\left(\varepsilon_{t-1}^{s p v}\right)^{2}+\beta_{s p v} h_{t-1}^{s p v}
\end{aligned}
$$

Equations: (4) and (5) show how volatility is transmitted over time across exchange rate and oil price volatility. The cross value of the error terms $\left(\varepsilon_{t-1}^{o p v}\right)^{2}$ and $\left(\varepsilon_{t-1}^{s p v}\right)^{2}$ represents the volatility innovations in the oil prices across the corresponding stock price movements at time (t-1) and represents the ARCH effect of past shocks, which captures the

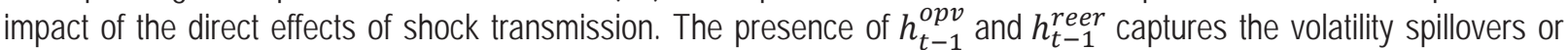
interdependencies between oil price volatility and the stock exchange prices. These variables show the GARCH effects of past volatilities which also indicate the persistence of volatility.

Based on the model shown above, the past shocks and volatility of oil prices are allowed to impact the future volatilities of stock prices in addition to its own future volatility. This model will also enable us estimate the conditional covariances between oil price volatility and stock prices in Nigeria.

\subsection{The Data}

We used quarterly data covering the period 1986 to 2012 for the empirical analysis in this study. The data are all sourced from the Central Bank of Nigeria Statistical Bulletin. In Figure 1, the trend in stock price and oil price volatilities is shown. The chart shows that both stock prices and oil prices have been volatile of the period although the volatility of oil prices has been deeper. In most of the sections in the chart, the volatility has gone the same direction, suggesting that crises or boom hit both prices in the same way. The deepest volatility was experienced during the 2007- 2009 financial crises when both prices degenerated rapidly and extensive. In this period also, oil prices experienced deeper volatility.

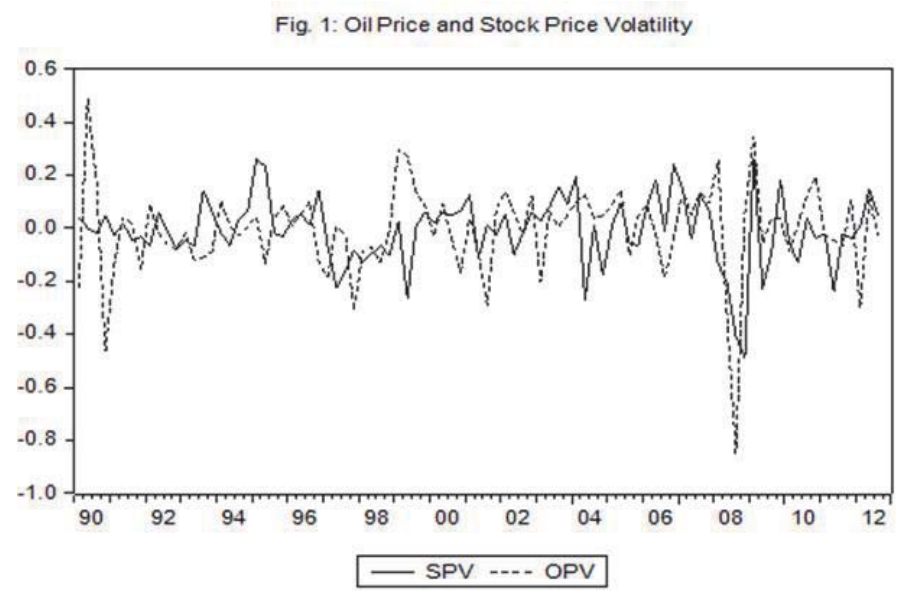

\section{Empirical Analysis}

The aim of this study is to show the main relationship existing between oil price and stock price volatility in Nigeria. This analysis requires extensive tests for time series characteristics in the data used for the analysis. Moreover, spillover effects of volatility between the variables are reported in the study. 


\subsection{Descriptive Statistics}

In order to, among other things, determine the distributional properties of stock and oil prices as well as their volatility, the descriptive statistics are presented. The summary statistics for the series in the sample for each of the markets is shown in Table 1 below. The average price of stocks for the period is 8.98 while that of oil prices is 3.51 . The average volatility for the two prices are similar at -0.1 over the period, showing that negative volatility dominates both markets. Stock prices have the highest volatility figure of 1.35 , though oil price volatility has the highest skewness value. This shows that though stock prices have varied more rapidly, oil price volatility were more scattered around the mean.

Included among the order statistics is the Jarque-Bera (J-B) statistic, which may be used to test normality. In particular, the hypothesis of normality is rejected for each of the variables by applying the Chi-Square distribution testing. Further evidence on the nature of deviations from normality may be gleaned from the sample skewness and kurtosis measures. While skewness of each series is always very close to zero (oil price volatility), the kurtosis is very large, especially for the volatility figures. This feature of the kurtosis, which measures the magnitude of the extremes, is quite interesting.

For each of the variables, the Ljung-Box portmanteau Q-statistic autocorrelations tests of eight lags rejects the null hypothesis of no autocorrelation in the standardized residuals in each of the variables but only rejects the null hypothesis of no autocorrelation in the standardized squared residuals in four stock prices and its volatility.

Table 1: Descriptive Statistics for Variables

\begin{tabular}{ccccc}
\hline & Stock price & Oil price & Stock price vol. & Oil price vol. \\
\hline Mean & 8.98 & 3.51 & -0.01 & -0.01 \\
Maximum & 11.05 & 4.93 & 0.26 & 0.49 \\
Minimum & 5.87 & 2.42 & -0.49 & -0.85 \\
Std. Dev. & 1.35 & 0.70 & 0.13 & 0.17 \\
Skewness & -0.65 & 0.52 & -0.73 & -1.28 \\
Kurtosis & 2.41 & 1.95 & 4.81 & 9.03 \\
Jarque-Bera & 7.65 & 8.34 & 20.50 & 162.84 \\
Probability & 0.02 & 0.02 & 0.00 & 0.00 \\
Q(8) & 3.53 & 3.79 & 1.64 & 3.93 \\
Q2(8) & 20.48 & 2.99 & 23.91 & 4.07
\end{tabular}

One way of further examining the distribution of the residuals in stock and oil price volatility is to plot the quantiles. The quantiles in this study are plotted using the Quantile-Quantile (Q-Q) theoretic plot and are shown in Figure 4.4a and 4.3b below. If the residuals are normally distributed, the points in the QQ-plots should lie alongside a straight line. The plots indicate that basically, both large negative and positive shocks are driving the departure from normality in each of the markets. As is seen in the charts, both the upper and lower tails in the plots deviate from the straight lines. Apparently, very large shocks (whether positive or negative) tend to degenerate in a series of deviations from long run patterns in the markets.

Fig. 2: Quantile Plots of Stock and Oil Price Volatility
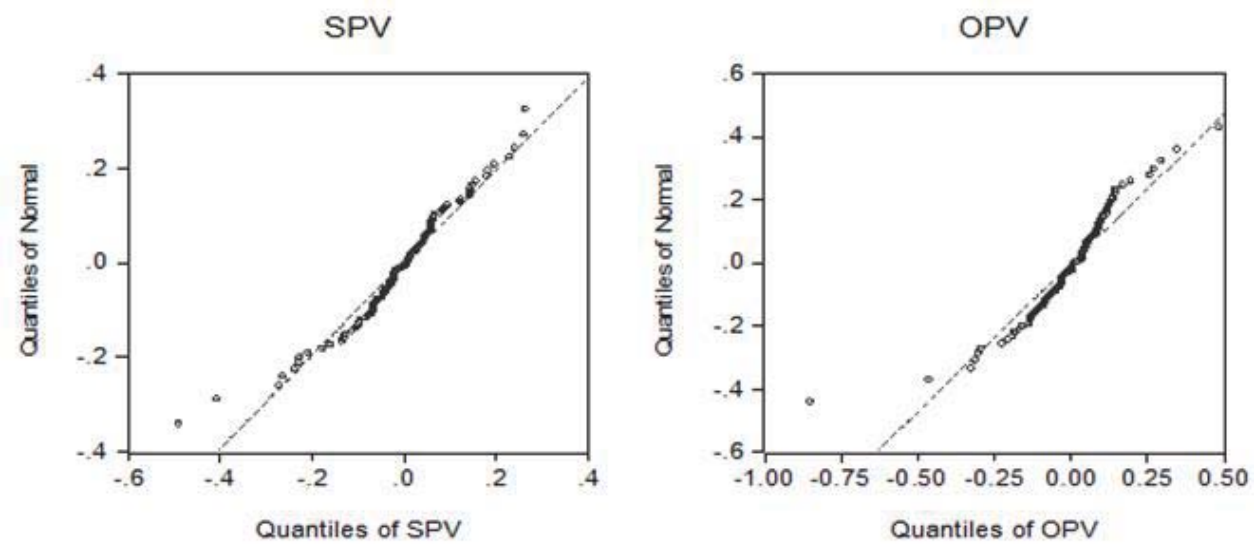
In order to further examine the background behavioural patterns in stock price volatility, the (unconditional or ordinary and conditional) correlation analysis is conducted on the data. It should be noted that the conditional correlation is explained as the correlations between the two variables after a shock on both variables. The correlation matrices for the variables are reported in Tables 2 below. Though both correlations are positive (suggesting same direction of movement), the unconditional correlation coefficient is less than that of the conditional volatility. This suggests that stock prices and oil prices tend to be more closely related in terms of volatility during a shock to either or both of them. By implication, both variables will move more closely together during a crisis boom.

Table 2: Correlation Matrix between Stock and Oil Price Volatility

\begin{tabular}{|c|c|}
\hline Type of correlation & Correlation \\
\hline Unconditional & 0.22 \\
\hline Conditional & 0.53 \\
\hline
\end{tabular}

Source: Author's computations

\subsection{Unit Root Tests}

The result of the ADF unit root test on the variables in levels and first differences is reported in Table 2 below. From the result, it is seen that the ADF test statistic for each of the variables in levels fails the significance test at the 95 percent critical level but the differenced variables all pass the test. With these result, these variables are adjudged to be difference-stationary attaining stationarity after first differencing. Thus, we would accept the hypothesis that the variables possess unit roots. Indeed, the variables are integrated of order one (i.e. I[1]). The ECM in Table 3 is stationary in levels and this (based on the Engle and Granger two stage test) indicates that the there is cointegration among the variables.

Table 3: Unit Root and ARCH Tests for Variables

\begin{tabular}{|c|c|c|c|c|}
\hline Variable & Levels & First differences & Order of Integration & ARCH LM Test \\
\hline$S P$ & -2.10 & $-3.66^{*}$ & $\mathrm{I}[1]$ & 4.82 \\
\hline OPV & -0.11 & $-5.52^{\star}$ & $\mathrm{I}[1]$ & 5.11 \\
\hline REER & -1.91 & $-5.17^{\star}$ & $\mathrm{I}[1]$ & - \\
\hline ECM & $-2.62^{\star}$ & - & $\mathrm{I}[0]$ & - \\
\hline
\end{tabular}

* shows significance at the 95 percent critical level ${ }^{* \star}$ shows significance at 5 percent

The result of the unit root test above also suggests that with the differenced variables, autocorrelation is absent since each of the differenced variables is stationary. However, the ARCH LM test for heteroskedasticity shows that the hypothesis of no heteroskedsacity for both SP and OPV cannot be rejected. Hence, it can be seen that these variables are heteroskedastic in their distribution which makes the application of an ARCH estimation technique plausible.

\subsection{The Single Equation Analysis}

Based on the aim of the study, we estimate the dynamic relationship between the dependent variable and all the independent variables based on the ECM specified in the previous section. The parsimonious results reported are based on the Scharze criterion selection. This result shows the pattern of short run behavior of stock prices in the presence of changes in oil price volatility and the other variables. The results in Table 4 below have quite impressive goodness of fit statistics even though the R squared just moderate and shows that 58 percent of the systematic short term variations in stock prices were captured in the model. 
Table 4: Short run Dynamic Results from the ECM

\begin{tabular}{|c|c|c|c|}
\hline Variable & Coefficient & t-Statistic & Prob. \\
\hline Constant & 0.592 & .071 & 0.00 \\
\hline$\Delta$ OPV & 0.221 & 2.53 & 0.01 \\
\hline$\Delta$ OPV(-1) & 0.207 & 2.48 & 0.01 \\
\hline$\Delta R E E R$ & -0.102 & -1.20 & 0.23 \\
\hline$\Delta R E E R(-1)$ & -0.069 & -.78 & 0.44 \\
\hline$\Delta R E E R(-2)$ & -0.322 & -3.64 & 0.00 \\
\hline$E C M(-1)$ & -0.077 & -3.33 & 0.00 \\
\hline$R$ squared $=0.323$ & $F=6.28$ & D.W. $=1.70$ & \\
\hline
\end{tabular}

From the results of the model, the coefficients of current and lagged oil price volatility are significant at the 5 percent level while that of real exchange rate is only significant for the second lag and is negative. This shows that oil price volatility have strong positive impacts on stock prices in the Nigerian Stock market. The volatility of oil prices tends to increase fluctuations in the stock prices which, more or less, implies that oil prices volatility causes deterioration in the stock market. The real exchange rate coefficient, on the other hand, indicates that depreciation of the naira may actually lead to stock price fall in Nigeria.

The coefficient of the error correction term in the result has the expected negative sign and is significant at the 1 percent level. This shows that any deviation in the stock prices in the short run will be restored in the long run.

\subsection{Multivariate Analysis (Volatility Transmission Results)}

The results of the estimated Bi-variate GARCH model using the Vector Conditional Heteroskedasticity (VECH) procedure is reported in Table 5 below. As mentioned in the previous chapter, volatility transmission from one variable to another is measured by considering the second moments of each of the variables. The VECH estimates report both the withinsample volatility and between variable volatility in the case of data in the series.

As shown in the results, both persistence and cross effects relationships are reported for the variables. The z-value for the coefficient of the ARCH term for SPV is 1.95 while that of OPV is 1.71. Thus, it can be seen from the results that both ARCH terms pass the 10 percent test. This indicates that news from previous period tends to affect the pattern of volatility of both stock and oil prices in Nigeria. The ARCH term for the cross variable is also significant at the 1 percent level and shows that news from previous periods tends to affect the pattern of interactions between the stock prices and oil price volatility.

We focus on the GARCH terms which show persistence in volatility for the individual variables and transmission of volatility for the variables. The spillover term passes the significance test at the 5 percent level since its z-value of 2.096 is greater than the 5 percent critical value of 1.96 . The results show that spill over from oil price volatility has a significant impact on stock prices in Nigeria. Given the positive coefficient of the spillover term, volatility in oil prices tends to stimulate volatility in stock prices in Nigeria. When the oil prices are fluctuate, such instabilities are transmitted into the Nigerian Stock market by generating or increasing volatility in stock prices. Thus, oil price volatility has a direct stimulating impact on stock prices as well as on stock price volatility in Nigeria. The conditional correlations shown in Table 2 also show that volatility in stock price would also intensify when volatility in oil prices increase.

Table 5: VECH spillover Results

\begin{tabular}{|l|c|c|c|}
\hline Relationship & Coefficient & z-Statistic & Prob. \\
\hline Sock price volatility constant & 0.009 & 1.110 & 0.267 \\
\hline Cross constants & 0.006 & 0.800 & 0.424 \\
\hline Oil price volatility constant & 0.014 & 2.644 & 0.008 \\
\hline SPV ARCH term & 0.906 & 1.952 & 0.051 \\
\hline Cross ARCH term & 0.842 & 1.804 & 0.071 \\
\hline OPV ARCH term & 0.809 & 1.710 & 0.087 \\
\hline Persistence in stock price volatility & 0.049 & 1.181 & 0.238 \\
\hline Persistence in oil price volatility & 0.179 & 1.956 & 0.051 \\
\hline Spill over between oil price volatility and exchange rate & 0.121 & 2.096 & 0.036 \\
\hline
\end{tabular}




\section{Conclusions}

This study set out to investigate the effect of oil price volatility on stock price in Nigeria using quarterly data from 1990 to 2012 period. It is well known that oil prices have exerted significant impacts on most macroeconomic variables in Nigeria (see Adegboye, 2013 and Akpan, 2009). This is the motivation for the current study. Given the pattern of the relationships, a dynamic framework was devised for the study. Hence, both statistical and econometric techniques were used for the analysis. Moreover, we argue that it is volatility in oil prices, not the levels that affect the stock prices. Thus, both the Error Correction Mechanism (ECM) and the Bi-variate GARCH model were used to test for the relationships and to check if volatility in oil prices are transmitted to stock prices in Nigeria. Based on the empirical analysis, we find that oil price volatility stimulates stock price changes in Nigeria. Moreover, oil price volatility generates and stimulates stock prices volatility in Nigeria. The basic indication of the modeling technique used in the study shows that volatility in oil prices are transmitted to stock price volatility.

The basic recommendation in this study suggests that incorporating the movement of international oil prices into stock price and returns expectations would help to ensure appropriate hedging against short term fluctuations in the Stock Market. Moreover, a holistic approach to the issues of sustainability given the oil price effects on the economy is needed. It is perhaps imperative for the central government to transform excess crude oil revenues into physical capital and infrastructure rather than distribute the windfalls to the state and local government, a situation that ensures easy transmission of oil prices into the Nigerian economy.

\section{References}

Adegboye, A.C. (2013). Fiscal policy and macroeconomic stabilisation in Nigeria:Are there institutional issues? Paper presented at the 54th Annual Conference of the Nigerian Economic Society in Abuja, 17th - 19th September.

Agren, M. (2006). Does oil price uncertainty transmit to stock markets? Department of Economics, Uppsala University, Working Paper 2006:23

Akpan, E. (2009). Oil price shocks and Nigeria's macro economy. Journal of Economics, Ibadan, 4(2): 12-19.

Arouri M., Lahiani, A. \& Nguyen, D. K. (2011). Return and volatility transmission between world oil prices and stock markets of the GCC countries. Economic Modelling 28(4), 1815 - 1825.

Basher, S.A., Sadorsky, P. (2006). Oil price risk and emerging stock markets. Global Finance Journal, 17, 224-251.

Bollerslev, T. (1986). Generalized autoregressive conditional heteroskedasticity. Journal of Econometrics 31; 307-327

Bollerslev, T.,(1990). Modelling the coherence in short-run nominal exchange rates: A multivariate generalized ARCH Model. Review of Economics and Statistics, 72, 498-505.

Bollerslev, T., Chou, R.Y. \& Kroner, K.F. (1992). ARCH Modelling in Finance: A Review of the Theory and Empirical Evidence', Journal of Econometrics, 52, 5-59.

Chan, F., Lim, C. and M. McAleer (2005). "Modelling Multivariate International Tourism Demand and Volatility," Tourism Management, Vol. 26, pp. 459-471.

Clark, P. K. (1973). A subordinated stochastic process model with fixed variance for speculative prices. Econometrica 41,135 - 156.

Engle, R. F. (1982). Autoregressive conditional heteroskedasticity with estimates of the variance of United Kingdom inflation. Econometrica 50; 987-1007.

Hammoudeh, S., Sari, R., \& Ewing, B. (2009). Relationships among strategic commodities and with financial variables: a new look. Contemporary Economic Policy, 27, 251-269.

Hasan, M. Z., \& Ratti, R. A. (2012). Oil price shocks and volatility in Australian stock returns. Paper presented at the Global Accounting, Finance and Economics Conference. Melbourne, VIC, 20-21 February.

Ling, S. and Mcaleer, M. (2003). On adaptive estimation in nonstationary ARMA models with GARCH Errors. The Annals of Statistics 31(2); 642-674.

Mensi, W., Makram, B., Boubaker, A. \& Managi, S. (2013). Correlations and volatility spillovers across commodity and stock markets: Linking energies, food and gold. Economic Modelling: 32: 15 - 22.

Omorokunwa, O.G \& Oviasogie, O.N. (2013). Interest and exchange rates volatility and the volatility of returns in the Nigerian Stock Market, Benin Journal of Social Sciences, 21(1),98-109.

Park, J. \& Ratti,R. (2008). Oil price shocks and stock markets in the U.S. and 13 European countries. Energy Economic, 30 (5), $2587-2608$.

Pindyck, R.S. (1991). Irreversibility, uncertainty and investment, Journal of Economic Literature, 29, 1110-1148.

Ramos, S.B. \& Veiga, H. (2010). Asymmetric effects of oil price fluctuations in international stock markets. Working Paper 10-09. Statistics and Econometrics Series (04).

Rentschler, J.E. (2013). Oil price volatility, economic growth and the hedging role of renewable energy. Policy Research Working Paper Series 6603 , The World Bank.

Ross, S.A. (1976). The Arbitrage Theory of Capital Asset Pricing. Journal of Economic Theory, 13, 341-60.

Sadorsky, P. (2004). Stock markets and energy prices. Encyclopedia of Energy Vol. 5 pp. 707-717. New York Elsevier.

Sauter, R. and S. Awerbuch (2003), Oil Price Volatility and Economic Activity: A Survey and Literature Review, IEA Research Paper, Paris.

Shaharudin, R.S, Samad, F., Bhat, S. (2009). Performance and volatility of oil and gas stocks: A Comparative Study on Selected O\&G Companies. International Business Research 2, (4), 87 - 99. 